\title{
Thermo and Electro-Switchable $\mathrm{Cs} \subset\left\{\mathrm{Fe}_{4}-\mathrm{Fe}_{4}\right\}$ Cubic Cage:
}

\section{Spin-Transition and Electrochromism}

\author{
Jana Glatz, ${ }^{a}$ Lise-Marie Chamoreau, ${ }^{a}$ Alexandrine Flambard, ${ }^{a}$ Jean-Francois Meunier, ${ }^{\mathrm{b}}$ Azzedine \\ Bouseksou $^{\mathrm{b}}$ and Rodrigue Lescouëzec*a
}

A mixed valence $\mathrm{Cs} \subset\left\{\mathrm{Fe}_{4}-\mathrm{Fe}_{4}\right\}$ cyanido-cube was synthesized and structurally characterized. The molecule, which is robust in solution, shows a remarkable electronic versatility. Electrochromic properties associated with nine different electronic states are observed in solution together with a thermo-induced spintransition in the solid state.

Molecular switches, i.e. molecules able to change their physical (optical, magnetic, etc.) properties under external stimuli are receiving intense research efforts because of their potential application in the fabrication of functional materials or nano-devices. ${ }^{1-3}$ In particular, redox active molecules ('redox switches') as well as magnetic switches such as spincrossover $(\mathrm{SCO})^{4}$ or charge-transfer ${ }^{5}$ complexes, open interesting opportunities in molecular electronics. ${ }^{6,7}$ In our group, inspired by anterior works on Prussian blue analogues (PBAs), ${ }^{8,9}$ we are particularly interested in using cyanide coordination chemistry for designing switchable molecules. Actually, the Prussian blue pigment, $\mathrm{Fe}_{4}{ }^{\text {III }}\left[\mathrm{Fe}{ }^{\prime \prime}(\mathrm{CN})_{6}\right]_{3}$, which is considered as the oldest synthetic coordination polymer, is a well-known electro-active material. In this compound, the intervalence charge transfer generates a deep blue colour that can be tuned by oxidation or reduction, to obtain Prussian brown (ferric ferricyanide) or Prussian white (ferrous ferrocyanide). This electrochromic property and the ability to deposit Prussian blue as thin films make this material useful for development of smart windows or other devices. ${ }^{10}$ The Prussian Blue analogues of general formula $A_{x} M_{y}\left[\mathrm{Fe}(\mathrm{CN})_{6}\right]_{z}$ ( $A$ is an inserted alkali ion, $M=C o, M n$ etc.), are also popular examples of switchable magnetic materials. In these systems, a metal-to-metal electron transfer can be triggered by light irradiation or temperature change, and lead to radical change in magnetic properties. In recent years, several groups have studied molecular models of PBA. ${ }^{11,12}$ For example, a cyanidebridged FeCo cubic complex showing a photomagnetic effect, with a remarkably long-life metastable state, was reported by Li et al. in $2008 .{ }^{13}$ In the same year, Nihei et al. reported the mixed valence cubic complex of formula $\left\{\left[\mathrm{Fe}^{\prime \prime}(\mathrm{Tp})(\mathrm{CN})_{3}\right]_{4}\left[\mathrm{Fe}^{\prime \prime \prime}(\mathrm{Tp})\right]_{4}\right\}$ (abbreviated from now $\left\{\mathrm{Fe}^{\prime \prime}{ }_{4}-\mathrm{Fe}{ }^{\prime \prime \prime}{ }_{4}\right\}$, $\mathrm{Tp}=$ hydro-tris(pyrazolyl)borate), which shows five reversibly accessible redox states associated with the oxidation/reduction of the $\left\{\mathrm{Fe}^{11 / I I I}(\mathrm{Tp})(\mathrm{CN})_{3}\right\}$ subunits. ${ }^{14}$ In our group, we recently investigated related $\left\{\mathrm{Fe}_{4}-\mathrm{CO}_{4}\right\}$ cubic complexes having similar blocking ligands but hosting an inserted alkali ion ( $A=K, C s$ ) inside the cage, as commonly found in PBA. Interestingly, the presence of the caesium ion interacting with the cage confers a remarkable stability to the polymetallic species in solution. ${ }^{15}$ Besides, these FeCo cubes show not only photomagnetic effect but also remarkable redox properties with nine accessible electronic states. In continuation of these works, we decided to extend our investigation toward $\mathrm{A} \subset\left\{\mathrm{Fe}_{4}-\mathrm{Fe}_{4}\right\}$ cubic complexes, assuming that both redox- and magnetic-switching could be obtained in the same molecule. Indeed, one of the Fe coordination sites in these cubes is made of a $\mathrm{N}_{6}$ coordination sphere, that is compatible with a spin-crossover phenomenon provided that: (i) the $\mathrm{Fe}$ is in the oxidation state $+\mathrm{II}$, (ii) the blocking ligand induces an adequate ligand field. Herein we show that inserting a $\mathrm{Cs}^{+}$ion into the original $\left\{\mathrm{Fe}_{4}-\mathrm{Fe}_{4}\right\}$ cyanide-bridged cube and using another blocking ligand than Tp allows isolating a cube with the targeted properties. We thus report the synthesis, structure and the electronic properties of the dual $\mathrm{Cs} \subset\left\{\mathrm{Fe}_{4} \mathrm{Fe}_{4}\right\}$ redox and magnetic switch. 


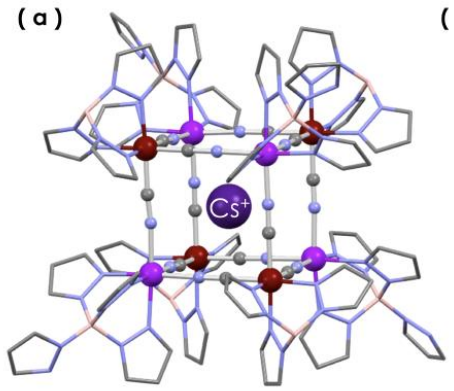

(b)
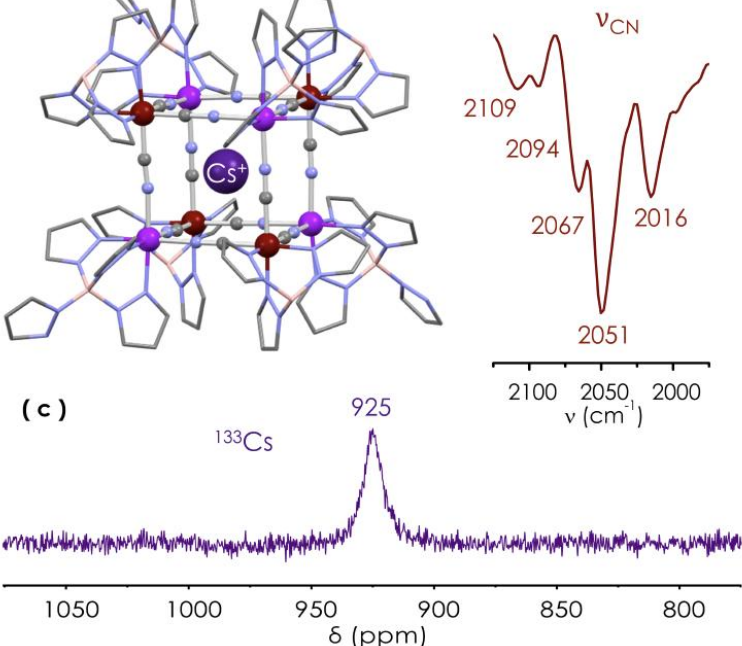

Figure 1. (a) XRD-structure of the $\mathrm{Cs} \subset\left\{\mathrm{Fe}_{4}-\mathrm{Fe}_{4}\right\}$ cube at $200 \mathrm{~K}$ : $\mathrm{Fe}^{\prime \prime}(\mathrm{Tp})$-site in cayenne and $\mathrm{Fe}^{\prime \prime \prime}(\mathrm{pzTp})$-site in violet. (b) FT-IR spectrum showing cyanide stretching bands (c) ${ }^{133} \mathrm{Cs}-\mathrm{NMR}$ of $\mathrm{Cs} \subset\left\{\mathrm{Fe}_{4}-\mathrm{Fe}_{4}\right\}$ in $\mathrm{CD}_{2} \mathrm{Cl}_{2}(400 \mathrm{MHz}, 300 \mathrm{~K})$.

The investigated complex, of formula CsC $\left\{\left[\mathrm{Fe}(\mathrm{Tp})(\mathrm{CN})_{3}\right]_{4}[\mathrm{Fe}(\mathrm{pzTp})]_{4}\right\}$ is obtained by the self-assembly of the $\left[\mathrm{Fe}^{\prime \prime \prime}(\mathrm{Tp})(\mathrm{CN})_{3}\right]^{-}$precursor with $\mathrm{Fe}^{\prime \prime}\left(\mathrm{ClO}_{4}\right)_{2}$ and $\mathrm{CsClO}_{4}$ salts and the blocking ligand pzTp (tetrakis(pyrazolyl)borate). It is abbreviated from now on as $\mathrm{Cs} \subset\left\{\mathrm{Fe}_{4}-\mathrm{Fe}_{4}\right\}$, where the first $\mathrm{Fe}_{4}$ refer to $\mathrm{Fe}$ linked to the $\mathrm{C}$ cyanide atoms (in the $\mathrm{FeC}_{3} \mathrm{~N}_{3}$ coordination sphere), while the second ones refer to Fe linked to the $\mathrm{N}$ cyanide atoms (in the $\mathrm{FeN}_{6}$ coordination sphere). As observed in Nihei's cube and in our $\left\{\mathrm{Fe}_{4}-\mathrm{CO}_{4}\right\}$ derivative, a metal-to-metal charge transfer occurs in solution during the synthesis. ${ }^{14,15}$ However, in contrast with the previously reported cubic complex $\left\{\mathrm{Fe}_{4}{ }_{4}-\mathrm{Fe}^{\mathrm{III}}{ }_{4}\right\}$, in the present case one of the Fe located in a $\mathrm{N}_{6}$ coordination sphere remains in $\mathrm{a}+\mathrm{Il}$ oxidation state. The complex is thus isolated in the electronic state $\mathrm{Cs} \subset\left\{\mathrm{Fe}_{4}{ }_{4}-\mathrm{Fe}^{\prime \prime \prime}{ }_{3} \mathrm{Fe}^{\prime \prime}\right\}$ (see below). This situation is analogous to that observed in the previously reported $\mathrm{Cs} \subset\left\{\mathrm{Fe}_{4}{ }_{4}-\mathrm{Co}^{\prime \prime \prime}{ }_{3} \mathrm{Co}{ }^{\prime \prime}\right\}$ counterpart: ${ }^{15}$ the cubic cage is monoanionic and its charge is counter balanced by the inserted caesium leading to a neutral molecule.

Single dark green rhombic crystals of the cube $\mathrm{Cs} \subset\left\{\mathrm{Fe}^{\mathrm{II}}{ }_{4}-\mathrm{Fe}^{\mathrm{II \prime}}{ }_{3} \mathrm{Fe} \mathrm{II}\right\}$ suited for X-ray diffraction were obtained by recrystallizing the in DMF precipitated cube in acetonitrile solution. The structure consists of two crystallographically independent octametallic cages (Fig.1a) containing an inserted caesium ion, acetonitrile and DMF crystallization molecules. The average $\mathrm{Fe}-\mathrm{C}$ and $\mathrm{Fe}-\mathrm{N}$ bond lengths of the $\left\{\mathrm{Fe}(\mathrm{Tp})(\mathrm{CN})_{3}\right\}$ subunits, $1.88(2)$ and $2.00(2) \AA$ (at $200 \mathrm{~K}$ ) respectively, are consistent with an $\mathrm{Fe}^{11}$ redox state. ${ }^{16}$ This is also confirmed by the cyanide stretching vibration (see below). The Fe-N average bond lengths of the $\left\{\mathrm{Fe}(\mathrm{pzTp})(\mathrm{CN})_{3}\right\}$ subunits are 2.043(18) $\AA$ for the cyanide nitrogen and 2.120 (17) $\AA$ for the Fe- $\mathrm{N}$ bond with the ligand. The exact location of the $\mathrm{Fe}{ }^{11} \mathrm{~N}_{6}$ site within the cube cannot be well identified by the Fe-N distances obtained by XRD data. The Fe"I-N and the Fe"-N distances (in an intermediate spin state at $200 \mathrm{~K}$ ) are too close to be distinguished. However, the distances between the central $\mathrm{Cs}^{+}$ion and the $\mathrm{FeN}_{6}$ ions in the corners are different: one distance, $4.20 \AA$ is shorter than the other three (ca. 4.42 $\AA$ ). We thus assume that the $\mathrm{Cs}^{+}$cation is preferably located close to the $\mathrm{Fe}^{11} \mathrm{~N}_{6}$ corners whose formal local charge is -0.5 (as the charge of iron is +2 , that of $T p$ is -1 , whereas that of each cyanide shared by two metal site is $-1 / 2$ ), maximizing the distance between the remaining three $\mathrm{Fe}^{\text {III }} \mathrm{N}_{6}$ corners (of formal local charge +0.5 ).

The FT-IR spectroscopy confirms the redox state of the four $\left\{\mathrm{Fe}^{\prime \prime}(\mathrm{Tp})(\mathrm{CN})_{3}\right\}$ subunits. Actually, the cyanide stretching vibrations are located at 2109, 2094, 2067 and 2051, $2016 \mathrm{~cm}^{-1}$ (Fig. 1), i.e in the expected range of the stretching peaks for bridging $\mathrm{Fe}^{\prime \prime}{ }_{\mathrm{LS}} \mathrm{CN}-\mathrm{M}$ cyanides ( $\mathrm{LS}=$ low spin) indicating that an electron-transfer is taking place during the reaction. The $C_{3 v}$ symmetry of the cube should lead to at least four different cyanide vibrations in solution. However, as shown by the XRD data there are 24 inequivalent $\mathrm{CN}$ ligands in the solid states. Furthermore, compared to the cube obtained by Nihei et al., all peaks are almost identical except for two new cyanide stretching bands centred at 2109 and $2016 \mathrm{~cm}^{-1}$, the latter are thus ascribed to the presence of the $\mathrm{Fe}^{11}{ }_{\mathrm{LS}}-\mathrm{CN}-\mathrm{Fe}^{\prime \prime}{ }_{\mathrm{HS}}$ bridges (beside the three $\mathrm{Fe}^{\prime \prime}{ }_{\mathrm{LS}}-\mathrm{CN}-\mathrm{Fe}{ }^{\prime \prime \prime}{ }_{\mathrm{HS}}$ links; $\mathrm{HS}=$ high-spin).
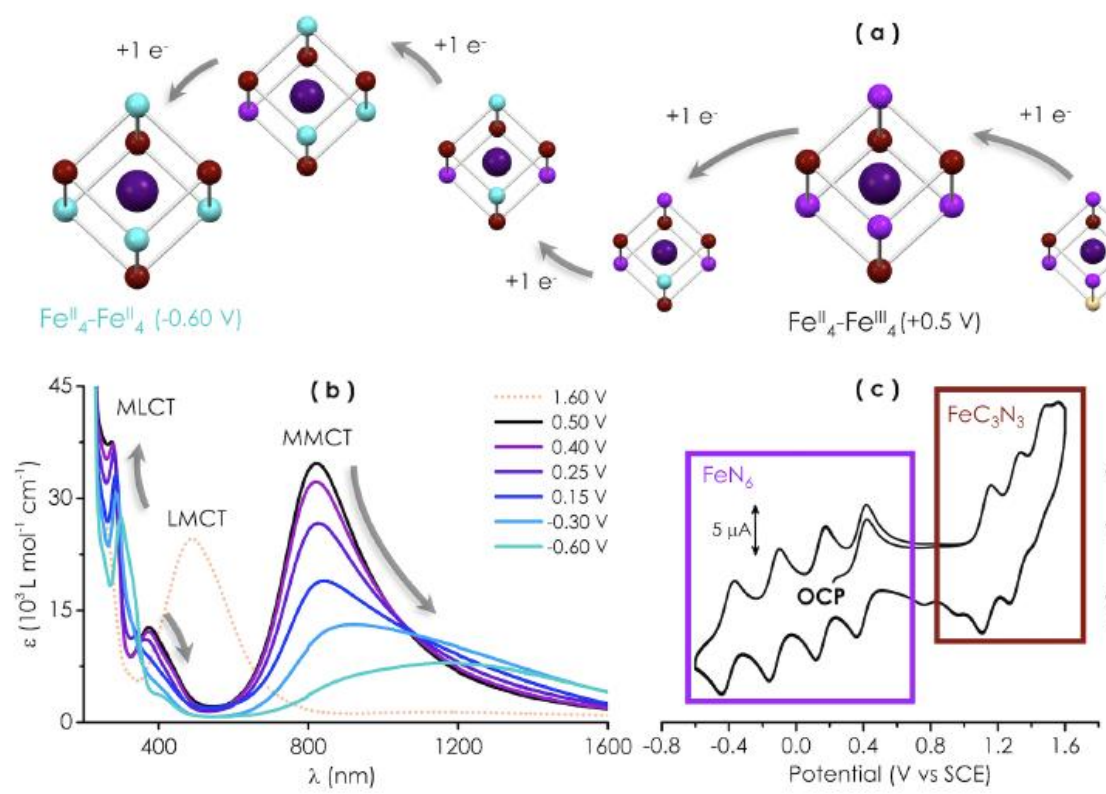

(a)
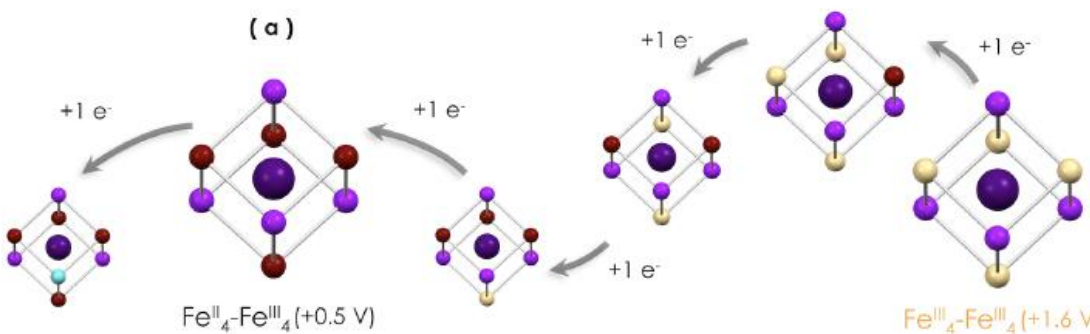

$\mathrm{Fe}^{11}-\mathrm{Fe}^{\mathrm{III}}(+1.6 \mathrm{~V})$

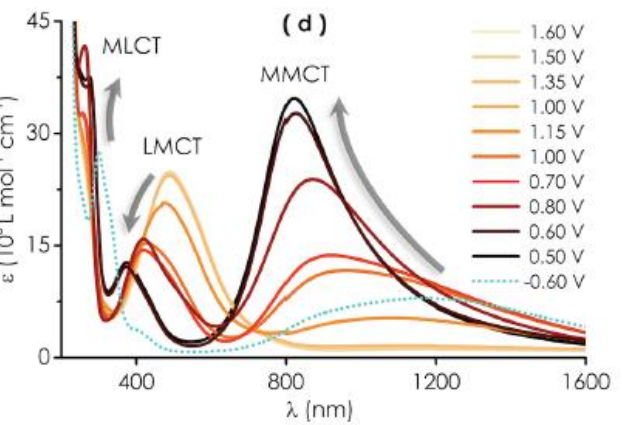

Figure 2. (a) Scheme of the 9 redox states of $\mathrm{Cs} \subset\left\{\mathrm{Fe}_{4}-\mathrm{Fe}_{4}\right\}$ accessible via cyclic-voltammetry (c) with $\left\{\mathrm{Fe}^{\prime \prime}(\mathrm{Tp})(\underline{\mathrm{NC}})_{3}\right\}$-site in dark red and $\left\{\mathrm{Fe}{ }^{\text {III }}(\mathrm{pz} T \mathrm{Tp})(\mathrm{CN})_{3}\right\}$-site in violet $\left(0.5 \mathrm{mM}\right.$; $0.1 \mathrm{M} \mathrm{NBu}_{4} \mathrm{PF}_{6}$ in $\mathrm{CH}_{3} \mathrm{CN}$; scan rate $100 \mathrm{mVs}^{-1}$ ). UV-Vis-spectra of $\left.\mathrm{Cs} \subset \mathrm{Fe}_{4}-\mathrm{Fe}_{4}\right\}$ at control applied potential from (d) high potential to (b) low potential. The black line corresponds to the $\mathrm{Cs} \subset\left\{\mathrm{Fe}_{4}{ }_{4}-\mathrm{Fe}^{\prime \prime \prime}{ }_{4}\right\}$ state. Gray lines are guides for the eyes for the evolution of the bands. 
The stability of the complex in organic solvent such as $\mathrm{CH}_{3} \mathrm{CN}$, $\mathrm{CH}_{2} \mathrm{Cl}_{2}$ and DMF was confirmed by ESI-MS spectrometry (Fig. S4) and NMR studies. Importantly, no degradation or oxidation of the $\mathrm{Cs} \subset\left\{\mathrm{Fe}^{\prime \prime}{ }_{4}-\mathrm{Fe}^{\prime \prime \prime}{ }_{3} \mathrm{Fe}^{\prime \prime}\right\}$ over time has been observed. The inserted caesium cation, which is known to have a very high affinity for the cubic cavity of PBAs, likely contributes to the robustness of the cube in solution, shielding the labile $\mathrm{FeN}_{6} \mathrm{HS}$ corner from ligand substitution. While the ${ }^{1} \mathrm{H}$ NMR exhibits only few broad features (Fig. S5.1), the ${ }^{133} \mathrm{Cs}$-NMR is more informative, showing only one strongly shifted peak at +925 ppm (vs. $\mathrm{CsNO}_{3}$, Fig.1). This feature confirms the presence of the $\mathrm{Cs}^{+}$ion inside one single paramagnetic cage, as previously observed for similar paramagnetic $\mathrm{Fe}_{4} \mathrm{M}_{4}$ cages. ${ }^{15,17,18}$ Cyclic voltammetry experiments in $\mathrm{CH}_{2} \mathrm{Cl}_{2}$ (Fig. S6) and $\mathrm{CH}_{3} \mathrm{CN}$ (Fig. 2c) also demonstrate the stability of the cage in solution and allow assessing the redox states of the metal ions. Two set of four quasi-reversible redox waves are observable: those of the $\left\{\mathrm{Fe}(\mathrm{Tp})(\underline{\mathrm{CN}})_{3}\right\}$ moieties above $0.9 \mathrm{~V}(\mathrm{vs} \mathrm{SCE})$ and those of the $\left\{\mathrm{Fe}(\mathrm{pzTp})(\underline{\mathrm{NC}})_{3}\right\}$ below $0.6 \mathrm{~V}$ (Fig. 2c). The open circuit potential $(\mathrm{OCP})$ at $0.20 \mathrm{~V}$, situated before the last oxidation wave of the first set (violet square), clearly shows that one of the $\left\{\mathrm{Fe}(\mathrm{pzTp})(\underline{\mathrm{NC}})_{3}\right\}$ ion is in its $+\mathrm{ll}$ reduced redox state. This result shows that the high stability and redox flexibility observed in solution in the $\mathrm{Cs} \subset\left\{\mathrm{Fe}_{4}-\mathrm{CO}_{4}\right\}$ cubes can be extended to other heterometallic cages. Interestingly, the multi-redox stability is associated with remarkable electrochromic properties as shown by the potential-controlled absorption spectra measured in the range of 200 to $2000 \mathrm{~nm}$ (Figure 2b,d). Schematically, one can distinguish three very distinct optical signatures associated with the different oxidation states of the cube, $\mathrm{Cs} \subset\left\{\mathrm{Fe}^{\prime \prime \prime \prime}{ }_{4}-\mathrm{Fe}^{\prime \prime \prime \prime}{ }_{4}\right\}, \mathrm{Cs} \subset\left\{\mathrm{Fe}_{4}{ }_{4}-\mathrm{Fe}^{\prime \prime \prime}{ }_{4}\right\}$ and $\mathrm{Cs} \subset\left\{\mathrm{Fe}_{4}{ }_{4}-\mathrm{Fe}{ }_{4}\right\}$, and the occurrence of different charge transfer (CT) bands. At high potential, in the $\mathrm{Cs} \subset\left\{\mathrm{Fe}^{\prime \prime \prime \prime}{ }_{4}-\mathrm{Fe}^{\text {III }}{ }_{4}\right\}$ state, the spectrum is dominated by an intense band centred at ca.489 $\mathrm{nm}$. This band can be ascribed to the ligand to metal charge transfer (LMCT) transitions, involving mainly the $\left\{\mathrm{Fe}^{\prime \prime \prime}(\mathrm{Tp})(\mathrm{CN})_{3}\right\}$ moieties. ${ }^{17}$ When reducing the cube up to its $\mathrm{Cs} \subset\left\{\mathrm{Fe}_{4}{ }_{4}-\mathrm{Fe}^{\mathrm{III}}{ }_{4}\right\}$ mixed valence state, this band loses intensity and seems to shift to the limit of the visible range, to $397 \mathrm{~nm}$. This contribution on the high energy side is actually ascribed to the LMCT of the $\left\{\mathrm{Fe}^{\text {IIII}}(\mathrm{pzTp})(\mathrm{NC})_{3}\right.$ moieties (details in $\mathrm{SI}$ ). Simultaneously two new bands appear in the spectrum. One is centred at $267 \mathrm{~nm}$ and it is assigned to the MLCT of $\left\{\mathrm{Fe}^{\prime \prime}(\mathrm{Tp})(\mathrm{CN})_{3}\right\}$ moieties. ${ }^{19}$ The other appears first at ca. 1100 $\mathrm{nm}$ at high potential and gradually transforms into an intense band centred at $820 \mathrm{~nm}$ in the $\mathrm{Cs} \subset\left\{\mathrm{Fe}^{\prime \prime}{ }_{4} \mathrm{Fe}^{\prime \prime \prime}{ }_{4}\right\}$ state. This very broad band is assigned to MMCT transitions. As suggested before, we assume that the charge transfer between first neighbours $\left\{(\mathrm{Tp}) \mathrm{Fe} \mathrm{e}^{\prime \prime \prime}-\mathrm{CN}-\mathrm{Fe}\right.$ "I $\left.(\mathrm{pzTp})\right\}$ gives rise to the transition located near $820 \mathrm{~nm}$, while that between second neighbours, $\left\{\mathrm{Fe}^{\prime \prime}(\mathrm{Tp})(\mathrm{CN})_{3}\right\} /\left\{\mathrm{Fe}^{\prime \prime \prime}(\mathrm{Tp})(\mathrm{CN})_{3}\right\}$, gives rise to the bands around $1100 \mathrm{~nm}^{14}$ All these observations are supported by the spectra obtained upon further reduction. When decreasing the potential, the MMCT band shifts back to $1100 \mathrm{~nm}$ as charge transfer between $\left\{\mathrm{Fe}^{\prime \prime}(\mathrm{pzTp})(\mathrm{NC})_{3}\right\} /\left\{\mathrm{Fe}^{\prime \prime \prime \prime}(\mathrm{pzTp})(\mathrm{NC})_{3}\right\}$ second neighbours are effective. In addition, the bands assigned to LMCT of Fe"l' units almost disappear, while other ones assigned

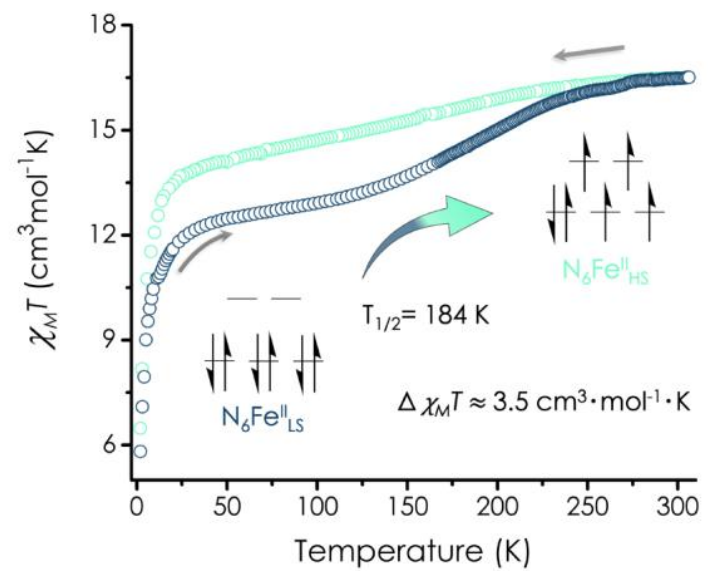

Figure 3. $\mathrm{XmT}$ vs. T plot $(2-310 \mathrm{~K}$ at $2 \mathrm{~K} / \mathrm{min})$ of freshly filtered $\mathrm{Cs}$ $\subset\left\{\mathrm{Fe}_{4}-\mathrm{Fe}_{4}\right\}$ crystals exhibiting a SCO (blue curve) that is irreversible upon heating too high (cyan curve)

to MLCT transitions of Fe" subunits shift to higher energy in the UV. In particular, the shoulder appearing at low potential is ascribed to the MLCT of the $\left\{\mathrm{Fe}^{\prime \prime}(\mathrm{pzTp})(\mathrm{NC})_{3}\right\}$ moieties.

The electronic properties of the cube in the solid-state were probed by magnetic measurements. We remind that the isolated neutral molecule corresponds to the $\mathrm{Cs} \subset\left\{\mathrm{Fe}_{4^{-}}\right.$ $\left.\mathrm{Fe}^{\prime \prime \prime}{ }_{3} \mathrm{Fe}^{\prime \prime}\right\}$ electronic state. Figure 3 shows the $X_{M} T$ versus $T$ curve where $X_{M}$ is the molar magnetic susceptibility per mol $\mathrm{Cs} \subset\left\{\mathrm{Fe}_{4}-\mathrm{Fe}_{4}\right\}$. The $X_{M} T$ value at room temperature, ca. 16.5 $\mathrm{cm}^{3} \mathrm{~mol}^{-1} \mathrm{~K}$, matches well with that expected for four $\mathrm{Fe}^{\prime \prime}{ }_{\mathrm{LS}}$, three $\mathrm{Fe}^{\prime \prime \prime}{ }_{\mathrm{HS}}$ and one Fe" ${ }_{\mathrm{HS}}$. Interestingly, the curve exhibits a sigmoidal shape centred at $T_{1 / 2}=184 \mathrm{~K}$, which is characteristic of spin-crossover compounds. This SCO is attributed to the $\left\{\mathrm{Fe}^{\prime \prime}(\mathrm{pzTp})(\underline{\mathrm{NC}})_{3}\right\}$ subunit which has a $\mathrm{N}_{6}$ coordination environment, typical for Fe" SCO complexes. Actually, the $X_{M} T$ variation between $100 \mathrm{~K}$ and $300 \mathrm{~K}, c a .3 .5 \mathrm{~cm}^{3} \mathrm{~mol}^{-1} \mathrm{~K}$, corresponds to that expected for a complete Fe" $\mathrm{SCO}$ (from $\mathrm{S}=$ 0 to $S=2$ ). It is worth noticing that the transition becomes irreversible (Fig. 3) if the sample is heated too much (up to 300 $\mathrm{K})$. This phenomenon is likely correlated to the desolvation of the sample as confirmed by our measurement on a previously dehydrated sample (S8) which remains in the HS state in the whole temperature range.

Finally, in order to confirm the electronic ground state of the $\mathrm{Cs} \subset\left\{\mathrm{Fe}{ }_{4}{ }-\mathrm{Fe}{ }^{\prime \prime \prime}{ }_{3} \mathrm{Fe}^{\prime \prime}\right\}$ cube, a powdered sample was measured by ${ }^{57} \mathrm{Fe}$ Mössbauer spectroscopy. The spectrum recorded at low temperature, $80 \mathrm{~K}$ (Fig. S10), is very similar to that obtained by Nihei et al. As expected, the contribution of four $\left\{\mathrm{Fe}^{\prime \prime}(\mathrm{Tp})(\mathrm{CN})_{3}\right\}$ subunits (ca. $52 \%$, i.e. $4 / 8$ of the iron), and three $\left\{\mathrm{Fe}^{\prime \prime \prime}(\mathrm{pzTp})(\mathrm{NC})_{3}\right\}$ subunits (ca. $35.5 \%$, i.e. $3 / 8$ of the iron) appear as quadrupole doublets with typical parameters for $\mathrm{Fe}^{\prime \prime}{ }_{\mathrm{LS}}\left(\mathrm{IS}=0.11 \mathrm{~mm} \mathrm{~s}^{-1}, \Delta E_{\mathrm{Q}}=0.46 \mathrm{~mm} \mathrm{~s}^{-1}\right)$ and $\mathrm{Fe}^{\mathrm{III}}{ }_{\mathrm{HS}}(\mathrm{IS}=0.49$ $\mathrm{mm} \mathrm{s}^{-1}, \Delta E_{\mathrm{Q}}=0.13 \mathrm{~mm} \mathrm{~s}^{-1}$ ), respectively. However, it is not possible to simulate the spectrum by just adding approximately $12.5 \%(1 / 8)$ of $\mathrm{LS}\left\{\mathrm{Fe}^{\prime \prime}{ }_{\mathrm{LS}}(\mathrm{Tp})(\mathrm{NC})_{3}\right\}$. A HS fraction (ca. $5.8 \%$ ) has to be introduced to reach a satisfactory simulation (ESI). The presence of such mixture of spin states for the $\left\{\mathrm{Fe}_{\mathrm{LS} / \mathrm{HS}}(\mathrm{TP})(\mathrm{NC})_{3}\right\}$ subunit is actually coherent with a partial desolvation of the sample during its preparation, 
associated with the irreversible spin-transition, as observed in magnetometry.

In summary, we report here a dual redox and magnetic molecular switch showing a rich electronic versatility. By changing the electric potential, the $\mathrm{Cs} \subset\left\{\mathrm{Fe}_{4}-\mathrm{Fe}_{4}\right\}$ cubic complex can be reversibly converted into nine electronic states. Consequently, LMCT, MLCT and MMCT bands can be reversibly switched on and off leading to at least three very different optical signatures. Moreover, a thermo-induced spintransition is observed in the solid-state for the neutral form. We are now investigating in more depth the influence of the nature of the alkali ion and blocking ligands on the electronic properties of a broader family of $A \subset\left\{\mathrm{Fe}_{4}-\mathrm{Fe}_{4}\right\}$ cages.

The authors thank Michel Verdaguer, Professor Emeritus, for his advices and support.

\section{references}

1 B. L. Feringa, Ed., Molecular switches, Wiley-VCH-Verl, Weinheim, 2011.

2 J. L. Zhang, J. Q. Zhong, J. D. Lin, W. P. Hu, K. Wu, G. Q. Xu, A. T. S. Wee and W. Chen, Chemical Society Reviews, 2015, 44, 2998-3022.

3 J. S. Lindsey and D. F. Bocian, Accounts of Chemical Research, 2011, 44, 638-650.

4 M. A. Halcrow, Ed., Spin-crossover materials: properties and applications, Wiley, Chichester, 2013.

5 Y.-S. Meng, O. Sato and T. Liu, Angewandte Chemie International Edition, 2018, 57, 12216-12226.

6 Z. Liu, Science, 2003, 302, 1543-1545.

7 E. Coronado, Nat Rev Mater, , DOI:10.1038/s41578-019-0146-8

8 S. Ferlay, T. Mallah, R. Ouahès, P. Veillet and M. Verdaguer, Nature, 1995, 378, 701.

9 V. Escax, A. Bleuzen, C. Cartier dit Moulin, F. Villain, A. Goujon, F. Varret and M. Verdaguer, Journal of the American Chemical Society, 2001, 123, 12536-12543.

10 P. M. S. Monk, R. J. Mortimer and D. R. Rosseinsky, Electrochromism and electrochromic devices, Cambridge University Press, Cambridge, 2007.

11 C. Mathonière, European Journal of Inorganic Chemistry, 2018, 2018, 248-258.

12 Y.-S. Meng, O. Sato and T. Liu, Angewandte Chemie International Edition, 2018, 57, 12216-12226.

13 D. Li, R. Clérac, O. Roubeau, E. Harté, C. Mathonière, R. Le Bris and S. M. Holmes, Journal of the American Chemical Society, 2008, 130, 252-258.

14 M. Nihei, M. Ui, N. Hoshino and H. Oshio, Inorg. Chem., 2008, 47, 6106-6108.

15 J.-R. Jiménez, M. Tricoire, D. Garnier, L.-M. Chamoreau, J. von Bardeleben, Y. Journaux, Y. Li and R. Lescouëzec, Dalton Trans., 2017, 46, 15549-15557.

16 A. Mondal, Y. Li, M. Seuleiman, M. Julve, L. Toupet, M. Buron-Le Cointe and R. Lescouëzec, Journal of the American Chemical Society, 2013, 135, 1653-1656.

17 J. Jiménez, J. Glatz, A. Benchohra, G. Gontard, L. Chamoreau, J. Meunier, A. Bousseksou and R. Lescouëzec, Angew. Chem., 2020, ange.201916199.

18 R. Plamont, J. Tami, J.-R. Jimenez, A. Benchohra, O. Khaled, G. Gontard, Y. Li and R. Lescouëzec, Journal of Coordination Chemistry, 2018, 71, 601-614.
19 E. D. Loutete-Dangui, E. Codjovi, H. Tokoro, P. R. Dahoo, S. Ohkoshi and K. Boukheddaden, Phys. Rev. B, 2008, 78, 014303. 